\title{
Scopoletin from Lasianthus lucidus Blume (Rubiaceae): A potential antimicrobial against multidrug-resistant Pseudomonas aeruginosa
}

\author{
Tiwtawat Napiroon ${ }^{1,2}$, Markus Bacher ${ }^{3}$, Henrik Balslev ${ }^{4}$, Kwankamol Tawaitakham ${ }^{5}$, Wichai Santimaleeworagun ${ }^{6 *}$, \\ Srunya Vajrodaya ${ }^{2 *}$ \\ ${ }^{1}$ The Forest Herbarium (BKF), Department of National Parks Wildlife and Plant Conservation, Bangkok 10900, Thailand. \\ ${ }^{2}$ Department of Botany, Faculty of Science, Kasetsart University, Bangkok 10900, Thailand. \\ ${ }^{3}$ Division of Chemistry of Renewables, University of Natural Resources and Life Sciences (BOKU), 3430 Tulln/Donau, Austria. \\ ${ }^{4}$ Department of Bioscience, Faculty of Science and Technology, Aarhus University, Aarhus C-8000, Denmark. \\ ${ }^{5}$ Department of Agricultural Resources, Kasetsart University, Sakon Nakhon 47000, Thailand. \\ ${ }^{6}$ Faculty of Pharmacy, Silpakorn University, Nakhon Pathom 73000 Thailand [A Novel Antibiotic Compound Project by Pharmaceutical Initiative for \\ Resistant Bacteria and Infectious Diseases Working Group (PIRBIG)].
}

\begin{tabular}{l}
\hline ARTICLE INFO \\
\hline Article history: \\
Received on: 03/05/2018 \\
Accepted on: 19/07/2018 \\
Available online: $30 / 09 / 2018$ \\
\hline Key words: \\
Ethnomedicines, Infectious \\
diseases, Scopoletin, \\
Lasianthus.
\end{tabular}

Lasianthus.

\begin{abstract}
A bioassay-guided study of stem bark lipophilic extracts led to the isolation of a bioactive compound from Lasianthus lucidus Blume species related to traditional medicine for treatment of wound infections, bleeding, and fevers. Scopoletin (7-hydroxy-6-methoxycoumarin) could be isolated from stem bark extract yielding $1.4 \mu \mathrm{mol} / \mathrm{g}$ by dry weight. The minimum inhibitory concentrations of extracts and scopoletin proved to be effective against both strains of Pseudomonas aeruginosa ATCC 27853 (AmpC $\beta$-lactamase producing strain) and P. aeruginosa DMSC 37166 (clinical strain). They revealed the highest antibacterial effect at $128 \mu \mathrm{g} / \mathrm{ml}$ and morphological changes on bacterial cells were demonstrated by Field Emission Scanning Electron Microscope. The lipophilic extracts and the purified scopoletin from $L$. lucidus have clear antibacterial activities, especially acting against $P$. aeruginosa strains. They produce cell lysis, inflated swelling cell walls and cell walls sinking into cells in the same way.
\end{abstract}

\section{INTRODUCTION}

Scopoletin is a phenolic coumarin isolated from many plants, known as an important compound of the phytoalexin group (Tal and Robeson, 1985). It has a yellow crystalline structure with a molecular weight of 192 and a melting point of $204-206^{\circ} \mathrm{C}$ (Vasconcelos et al., 1998). Its various biological activities have been reported through a number of investigations. Booth et al. (2004) reported that such compound produced specific biological activities and possible health implications for humans in food

\footnotetext{
${ }^{*}$ Corresponding Author

Srunya Vajrodaya, Department of Botany, Faculty of Science, Kasetsart University, Bangkok, 10900,Thailand.E-mail:fscisyv@ku.ac.th; Wichai Santimaleeworagun, Department of Pharmacy, Faculty of Pharmacy, Silpakorn University, Nakhon Pathom, 73000, Thailand. E-mail: swichai1234@gmail.com
}

and medicine. In clinical uses, scopoletin and the substance class of coumarins were described and tested for treating anticonvulsant properties, cardiovascular and neuromuscular symptoms (Adesina, 1982) as well as an anti-diabetic agent, use in alleviating insulin resistance and anticoagulant (Chang et al., 2015). For infectious diseases, coumarins and scopoletin were described as potentially exhibiting antibacterial activity against bacteria such as Staphylococcus aureus, Pseudomonas aeruginosa, Bacillus cereus and Escherichia coli (Souza et al., 2005 and Deng et al., 2007). In an animal model study, Panda and Kar (2006) demonstrated that scopoletin at a low dose $(1 \mathrm{mg} / \mathrm{kg})$ had the potential to regulate hyperthyroidism and hyperglycemia. Obasi et al. (1996) and Moon et al. (2007) suggested the possible role of dietary scopoletin in some disorders of blood clotting and lipid metabolism in animals and effects on inflammation acting on mast cells. Scopoletin has served an important role for a long time 
in traditional medicine in Africa, Asia, and Europe. Several plant families, e.g. Aceraceae, Asteraceae, Euphorbiaceae, Fabaceae, Rubiaceae, Combretaceae, Meliaceae, Rutaceae, Solanaceae etc. contain high yields of scopoletin and are used as medicine for convulsion symptoms and rheumatic pain. The fruit and seeds of Tetrapleura tetraptera (Fabaceae) are used in Nigeria and Ghana, while the fruit of Physalis alkekengi (Solanaceae) is used to reduce inflammation in Colombia (Ojewole and Adesina, 1983; Xia et al., 2007). The juice from the fruits and leaves of Morinda citrifolia (Rubiaceae), namely known as "Noni" in the Asia Pacific, are used for the treatment of diabetes, regulation of blood pressure and as a poultice on wounds (Handy et al., 1934; McClatchey, 2002). In 2003, the official journal of the European Union reported that the European Commission approved that "Noni" fruit juice was a novel and safe health food in Europe. In addition, Nawrot et al. (2013) and Dai et al. (2018) reported that scopoletin isolated from the stem bark of Cedrelopsis rakotozafyi Cheek \& Lescot (Rutaceae) used as febrifuges or reduce fevers. Additionally, the new coumarins were discovered from the roots of Terminalia trophophylla $\mathrm{H}$. Perrier (Combretaceae) and the stem bark of Astrotrichilia sp. (Meliaceae) revealed potentially activities against A2780 human ovarian cancer cell line (Dai et al., 2018).

Lasianthus lucidus Blume species of the coffee family (Rubiaceae) is a shrub native to tropical and subtropical regions of Asia, especially in tropical regions of China, India and Southeast Asia. The species grows in primary forests, with occasional records from disturbed forests or forest edges (Robbrecht, 1988; Cai et al., 2005; Zhu et al., 2012). Interestingly, the leaves and stem bark extracts have been reported for its potentially antibacterial property against Pseudomonas aeruginosa (Rai and Lalramnghinglova, 2011; Napiroon et al., 2017a; Napiroon et al., 2017b). Pseudomonas aeruginosa is one pathogenic bacterium in the list of antimicrobials resistant or superbugs for surveillance and monitoring by the World Health Organization (WHO) reports (WHO, 2017). Developing novel antimicrobial agents against $P$. aeruginosa is a much more difficult task because of the presence of decrease membrane permeability and multidrug efflux pumps (Morita et al., 2014).

Lasianthus lucidus was currently studied in our laboratories and was used in traditional medicine to stop bleeding from wounds and applied to reduce fever which caused by infections (Rai and Lalramnghinglova, 2011). Consequently, we hypothesize that the bioactive compounds from L. lucidus extract may have antibacterial effects. To test this hypothesis, we did plant extraction and isolation of a pure compound found in the species and finally tests their anti-pseudomonad action.

\section{MATERIALS AND METHODS}

\section{Plant material}

Mature leaves and stem bark of L. lucidus were collected during the fruiting stage between November and December 2016, from hill evergreen forests in Thailand. Voucher specimens of $L$. lucidus (collector no. NT015) were deposited at the Department of Botany, Kasetsart University, Bangkok Forest Herbarium (BKF), and Aarhus University Herbarium (AAU). Comparisons were made with type specimens of the species at the $\mathrm{K}$ and $\mathrm{L}$ herbaria, using photographs available on the web and related literature (Zhu et al. 2012). Plant samples were observed under a stereo microscope. Herbarium acronyms follow Index Herbariorum (sweetgum.nybg.org/science/ih/).

\section{Plant extractions}

Mature leaves and stem bark were separated and dried under shade, chopped into small pieces and powdered using an electronic mill. $200 \mathrm{~g}$ of the powder was macerated with methanol $\left(\mathrm{CH}_{3} \mathrm{OH}\right)$ for seven days in the dark at room temperature. Subsequently, extracts were filtered through Whatman No.1 filter paper and then concentrated by rotary evaporation at $37^{\circ}$ to $39^{\circ} \mathrm{C}$, until the crude extracts were semi-solid. The concentrated crude extracts were partitioned to a hydrophilic extract in distilled water and lipophilic extract in chloroform. The lipophilic extracts were stored at a temperature below $-45^{\circ} \mathrm{C}$.

The lipophilic extracts were placed on Thin Layer Chromatography (TLC) precoated silica gel $60 \mathrm{~F}_{254}$ plates $(20 \times$ $20 \mathrm{~cm}$; Merck) using a solvent system of hexane:ethyl acetate $(7: 3 \mathrm{v} / \mathrm{v})$ and detected under UV irradiation $(365 \mathrm{~nm}$ and $254 \mathrm{~nm})$. The Rf values of each fluorescent spot were determined as a TLC pattern. For high-performance liquid chromatography (HPLC) analysis, samples of $10 \mathrm{mg} / \mathrm{mL}$ of lipophilic extracts and the pure compounds in methanol $\left(\mathrm{CH}_{3} \mathrm{OH}\right.$; HPLC grade, Merck) were prepared and filtered through a $0.45 \mu \mathrm{m}$ nylon filter using a solvent system, $60 \% \mathrm{v} / \mathrm{v}$ methanol gradient 60 to $100 \%$ (HPLC grade; Merck) in $40 \% \mathrm{v} / \mathrm{v}$ aqueous buffer ( $0.015 \mathrm{M}$ orthophosphoric acid $\mathrm{pH} 3$ and $0.015 \mathrm{M}$ tetrabutylammonium hydroxide) that followed suitable mobile phase for coumarins detection (Vajrodaya 1998 and Vajrodaya et al. 1998). The HPLC analysis was performed with Agilent 1100 series and was detected by UV photodiode arrays detector with wavelengths of $230 \mathrm{~nm}, 254 \mathrm{~nm}$, and $280 \mathrm{~nm}$, respectively.

\section{Isolation}

The bioactive compound was evaluated using medium pressure liquid chromatography (MPLC) technique. Stem bark lipophilic extract (670 $\mathrm{mg}$ dissolved in $6 \mathrm{ml} \mathrm{MeOH})$ was applicated onto a glass column $(400 \times 40 \mathrm{~mm}$, Büchi) filled with silica gel 25 to $40 \mu \mathrm{m}$ (Merck LiChroprep Silica gel 60, 25-40 $\mu \mathrm{m})$ as an absorbent using a flow rate of $12 \mathrm{ml} / \mathrm{min}$. A pressure of about 4 bars was used (pump model 1-10 bar, Fluid Metering, Chromatographic pump from Combiflash, USA). Fractions of 50 $\mathrm{ml}$ were collected with the following solvent system: First, 30\% ethyl acetate in hexane was collected in 7 fractions (fractions 1 to 7). Next, $50 \%$ ethyl acetate in hexane was collected in 9 fractions (fractions 8 to 16 ) followed by $70 \%$ ethyl acetate in hexane collected in 9 fractions (fractions 17 to 25). The column was washed and calibrated with methanol (Analytic grade, Merck) before and after each run for 30 min with the pressure set to 4 bars and a flow rate of $12 \mathrm{ml} / \mathrm{min}$.

All fractions were checked for purity with thin layer chromatography (TLC) and UV detection (wavelength 365 $\mathrm{nm}$ ). Fractions with similar composition (fraction 14-20) were combined and recrystallized with diethyl ether to give $54 \mathrm{mg}$ of pure scopoletin in form of yellow crystals and then $10 \mathrm{mg}$ of scopoletin was dissolved in DMSO for bioassay tests. 


\section{Antibacterial activity}

For antimicrobial assays, plant extracts were evaluated using two pathogenic bacterial strains from the Department of Medical Science, Ministry of Public Health, Thailand: Pseudomonas aeruginosa ATCC 27853 (AmpC $\beta$-lactamase producing strain) and $P$. aeruginosa DMSC 37166 (Clinical strain). The quality control of the Clinical and Laboratory Standards Institute (CLSI 2017) for standardized sensitivity test, $P$. aeruginosa ATCC 27853 was used as positive control species with standard antibiotic including; AMK (Amikacin $30 \mu \mathrm{g}$ ), CIP (Ciprofloxacin $5 \mu \mathrm{g}$ ) and PIP/TAZ (Piperacillin/Tazobactam $100 / 10 \mu \mathrm{g})$.

The minimum inhibitory concentration (MIC) of extracts and pure compound were determined using the broth microdilution method. Stock solutions of $10 \mathrm{mg} / \mathrm{mL}$ which corresponds to $0.91 \%$ $\mathrm{w} / \mathrm{w}$ (prepared by dissolving each extract and pure compound in dimethyl sulfoxide (DMSO-Sigma-Aldrich, USA) was serially diluted with 2-fold concentrations. Standard inocula of test bacteria in Mueller-Hinton broth (MHB-Oxoid, Basingstoke, UK) were placed in separated wells of a 96-well plate using DMSO as the control. The organisms were cultivated at $37^{\circ} \mathrm{C}$ for 18 hours. The MIC was documented as the lowest concentration of extracts that inhibited visible growth.

\section{Field Emission Scanning Electron Microscopy (FE-SEM)}

For field emission scanning electron microscopy (FESEM), the suspensions of Pseudomonas aeruginosa ATCC 27853 (AmpC $\beta$-lactamase producing strain) and $P$. aeruginosa DMSC 37166 (Clinical strain) of $105 \mathrm{CFU} / \mathrm{mL}$ in lipophilic extracts and scopoletin at the lowest MIC concentrations combined with Mueller-Hinton Broth (MHB) were incubated at $37^{\circ} \mathrm{C}$ for six hours and then filtered through $0.22 \mu \mathrm{M}$ filter paper. The bacteria on the filter paper were fixed with $2.5 \%$ glutaraldehyde in $0.2 \mathrm{M}$ sodium phosphate saline buffer $(\mathrm{pH} 7.2)$ for 12 hours at $4^{\circ} \mathrm{C}$. The fixed bacteria were washed three times with $0.2 \mathrm{M}$ sodium phosphate saline buffer ( $\mathrm{pH} 7.2)$ for about 15 minutes each time and then post-fixed with $1 \%$ osmium tetroxide $(\mathrm{OsO} 4)$ in distilled water for one hour applying the method of cell fixation from Cardozo et al. (2013). After that, the filter paper was cleaned up using three cycles (15 minutes) of distilled water. The fixed samples were dehydrated in gradient acetone concentrations (20, 40, 60, 80 and 100\%) and then dried at a critical point of CO2 (Polaron Range SC7620 Sputter Coater \& CA7625 Carbon Accessary). Finally, the filter paper on the carbon tape was coated with platinum (AUTOLAB, Spin coater) and observed under an FE-SEM (HITACHI FE-SEM SU8010 Ultra-High Resolution (1.0 nm); Japan).

\section{RESULTS}

\section{Chromatographic analyses of stem bark extracts and pure compound}

The HPLC profiles showed four dominant peaks in leaf extracts while only one dominant peak appeared in stem bark extracts. The results showed that the chemical characters of stem bark lipophilic extract present similar characteristics to the pure compound at an approximate retention time of $3.7 \mathrm{~min}$ in the same mobile phase. HPLC chromatograms of both stem bark lipophilic extract and the pure compound are provided in Figure 1. Pure scopoletin had a retention time of approximately $3.7 \mathrm{~min}$, the UV spectra, and HPLC chromatogram is shown in Figure 2.

After fractionation combination of fraction 14 to 20 appeared as fluorescent light blue spots on developed TLC plates (solvent system, hexane:ethyl acetate $(7: 3 \mathrm{v} / \mathrm{v}))$, when observed under UV irradiation, at wavelength $365 \mathrm{~nm}$. The fractions produced the most intense fluorescent light blue spot. The stem bark extract of L. lucidus and the fractions also produced the same spot with a relative front (Rf) of 0.5 (Figure 1).

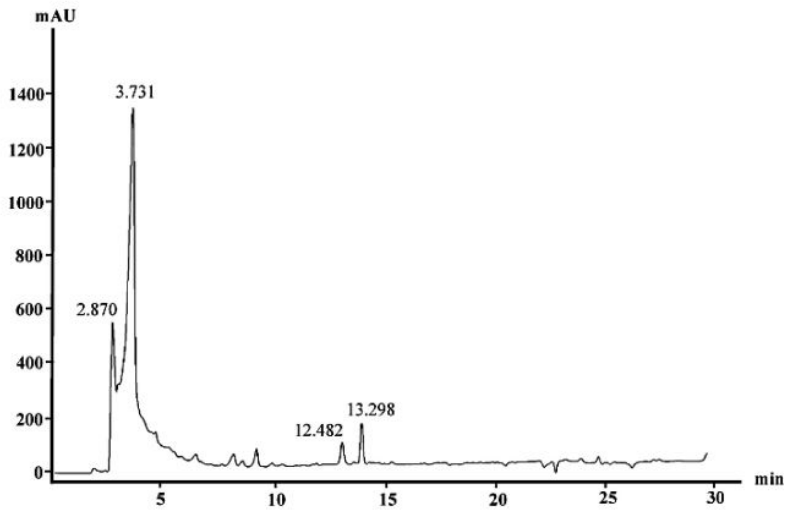

A. Stem bark lipophilic extract

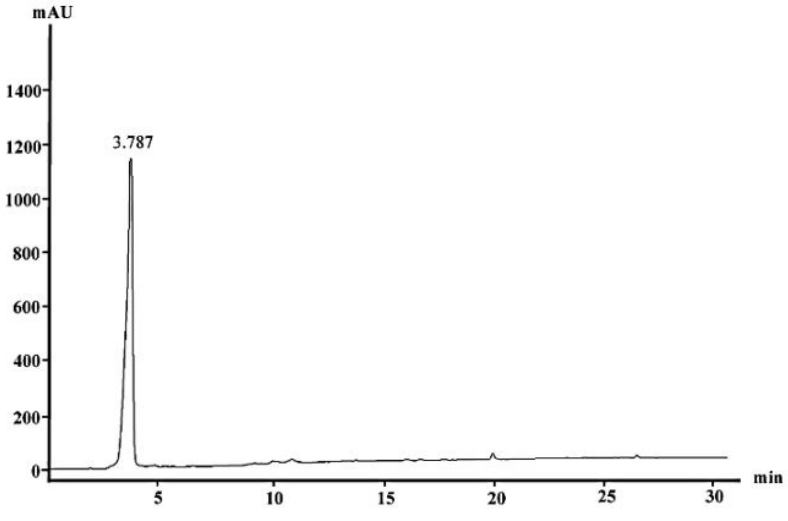

B. Scopoletin

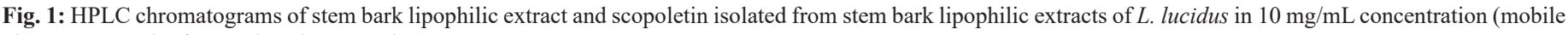
phase; aqueous buffer: methanal, 40:60 v/v).

\section{Pure compound and Nuclear Magnetic Resonance (NMR) structure elucidation}

The yellowish crystalline illuminated blue fluorescence under UV light (wavelength $365 \mathrm{~nm}$ ) and showed the physical property using $1 \mathrm{D}\left({ }^{1} \mathrm{H}, \mathrm{NOE}\right)$ and $2 \mathrm{D}$ (HSQC) NMR as following; ${ }^{1} \mathrm{H}$ NMR (400 MHz, AcCN) $\delta: 3.90$ (3H, s, OMe), 6.18 (1H, d, $J$ $=9.5 \mathrm{~Hz}, \mathrm{H}-3), 6.82(1 \mathrm{H}, \mathrm{s}, \mathrm{H}-8), 7.09(1 \mathrm{H}, \mathrm{s}, \mathrm{H}-5), 7.75(1 \mathrm{H}, \mathrm{d}$, $J=9.5 \mathrm{~Hz}, \mathrm{H}-4)$. The ${ }^{1} \mathrm{H}$ NMR spectrum of the pure compound 
showed two doublets at $\delta 6.18 \mathrm{ppm}$ and $\delta 7.75 \mathrm{ppm}$ (each, $1 \mathrm{H}, \mathrm{d}$, $J=9.5 \mathrm{~Hz}$ ), characteristic of $\mathrm{H}-3$ and $\mathrm{H}-4$ protons of the pyrone ring. In addition, two singlets at $\delta 6.82 \mathrm{ppm}$ and $\delta 7.09 \mathrm{ppm}$ were assigned to $\mathrm{H}-5$ and $\mathrm{H}-8$, respectively, a three proton singlet at $\delta$ $3.90 \mathrm{ppm}$ was attributed to 6-O-methyl group and melting point of $204-206^{\circ} \mathrm{C}$. The NMR data are in agreement with those of reported ones for scopoletin. NMR spectra were recorded on a
Bruker Avance II 400 (resonance frequencies $400.13 \mathrm{MHz}$ for ${ }^{1} \mathrm{H}$ and $100.63 \mathrm{MHz}$ for ${ }^{13} \mathrm{C}$ ) equipped with a $5 \mathrm{~mm}$ observe broadband probe head (BBFO) with z-gradients at room temperature. The sample was dissolved in $0.6 \mathrm{ml}$ of $\mathrm{CD}_{3} \mathrm{CN}(99.8 \% \mathrm{D})$. Chemical shifts are given in ppm, referenced to residual solvent signals (1.94 ppm for $\left.{ }^{1} \mathrm{H}\right)$.

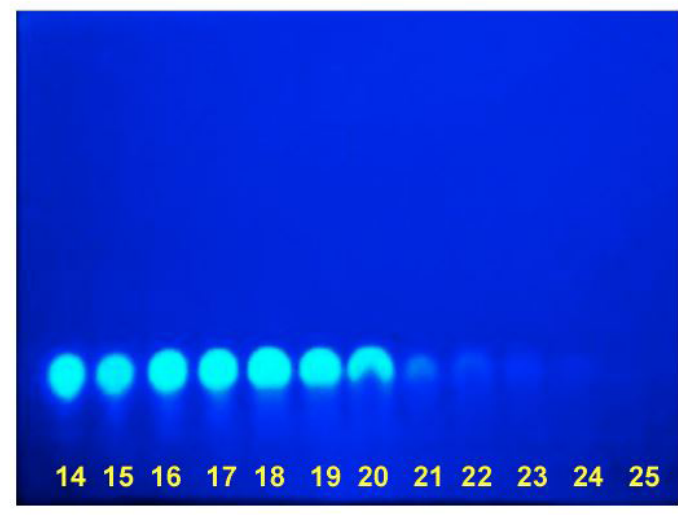

A

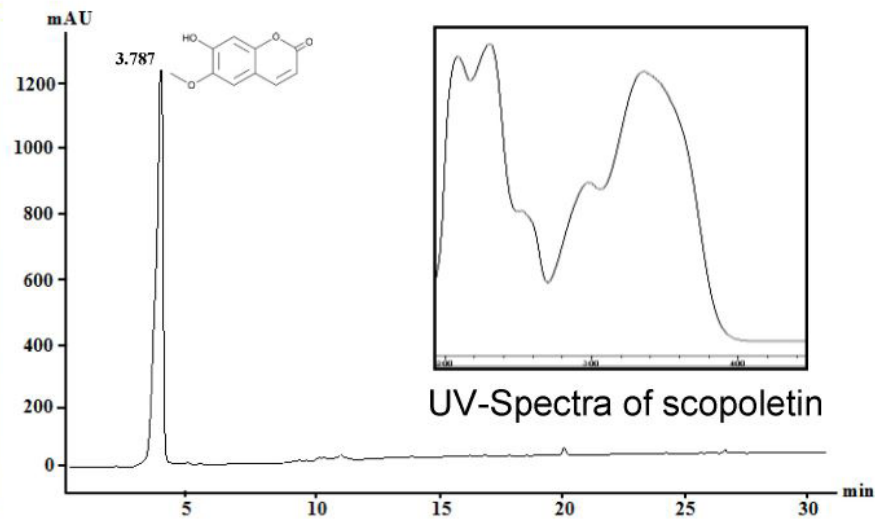

B

Fig. 2: A. TLC chromatogram of scopoletin isolated from L. lucidus, dissolved with methanol in mobile phase; hexane:ethyl acetate (7:3 v/v) B. HPLC chromatogram and UV spectra of scopoletin (combined fractions 14 to 20), dissolved with methanol in mobile phase; aqueous buffer:methanol (40:60 v/v).

The chemical structure of scopoletin (7-hydroxy-6methoxy coumarin) is shown in Figure 3.<smiles>COc1cc2ccc(=O)oc2cc1O</smiles>

Fig. 3: Scopoletin (7-Hydroxy-6-methoxycoumarin).

\section{Antibacterial activity}

The MIC tests of the plant extracts exhibited the highest efficacy against both strains of $P$. aeruginosa (DMSC 37166 and ATCC 27853) (Table 1). The MICs of L. lucidus leaf extract, stem bark extract, and scopoletin were 256, 128 and $128 \mu \mathrm{g} / \mathrm{ml}$, respectively. The lipophilic stem bark extract and pure scopoletin had equal effective inhibitory effects on $P$. aeruginosa ATCC 27853 (AmpC $\beta$-lactamase producing strain) at $128 \mu \mathrm{g} / \mathrm{ml}$ as shown in Table 1.

\section{Field Emission Scanning Electron Microscopy (FE-SEM)}

FE-SEM analysis showed significant morphological changes in $P$. aeruginosa ATCC 27853 after exposure to lipophilic extracts and scopoletin regarding its MIC value. The extracts clearly produced cellular lysis, an inflated swelling appeared on cell walls and cell elongation when compared with untreated bacteria (control) (Figure 4).

\section{DISCUSSION}

The separation of extracts was done by using MPLC technique with a suitable mobile phase, TLC and HPLC were used to determine and investigate the purity of the isolated compounds (Kupiec, 2004 and Lukaza and Minika, 2009). Our HPLC process was confirmed in triplicate testings that showed all the similar UV spectra information of scopoletin. This result showed the similar UV spectrum ( $\chi \max$ ) as the information of scopoletin from the previous report of Ferdinal et al. (2015).

Table 1: Inhibitory effects (MIC, $\mu \mathrm{g} / \mathrm{ml})$ of extracts and scopoletin from $L$. lucidus against Pseudomonas aeruginosa.

\begin{tabular}{ccc}
\hline \multirow{2}{*}{ Compounds* } & \multicolumn{2}{c}{ MIC $\boldsymbol{\mu g} / \mathrm{mL}$} \\
\cline { 2 - 3 } & $\begin{array}{c}\boldsymbol{P} \text {. aeruginosa ATCC 27853 (AmpC } \\
\boldsymbol{\beta} \text {-lactamase producing strain) }\end{array}$ & $\begin{array}{c}\boldsymbol{P} \text { a aeruginosa } \text { DMSC } \\
\mathbf{3 7 1 6 6} \text { (Clinical strain) }\end{array}$ \\
\hline Leaf extract & 256 & 256 \\
Stem bark extract & 128 & 128 \\
Scopoletin $(\mu \mathrm{M})$ & 0.66 & 0.66 \\
\hline
\end{tabular}

*Each sample was tested in triplicate.

Of our study, both chromatographic techniques helped to discover scopoletin from stem bark lipophilic extract of L. lucidus. The profiles may provide prediction tools of accumulation trends which can be expected in yet unstudied, but closely related species within a genus, thus facilitating the investigation for bioactive compounds (Murray et al., 1982). Our study also detected coumarins and the firstly isolated scopoletin from stem bark lipophilic extract of L. lucidus (Rubiaceae). Similarly, Murray et al. (1982) collected information of the coumarin group found in Rubiaceae such as the species in genus Morinda, Hymenodictyon and Hedyotis etc. (Gnonlonfin et al., 2012). These species contained scopoletin (7-hydroxy-6-methoxycoumarin) either in leaves, stem bark and roots. It has been found in several other plants revealing different concentrations in each plant part (Ishikura et al., 1979). In 1979 Ishikura et al. described for the first time the occurrence of scopoletin in Lasianthus by isolating it from L. japonicus. We isolated scopoletin from $L$. lucidus yielding $1.4 \mu \mathrm{mol} / \mathrm{g}$ from stem bark, (200 g dry weight), that gave the highest yield of scopoletin 
when compared with related reports in other plants, i.e. the report of yields from Gnonlonfin et al. (2012).

Regarding the role in defense, scopoletin has shown potential antibacterial properties, i.e. coumarins and scopoletin, detected in Morinda citrifolia (Rubiaceae) or Noni, inhibiting the growth of certain pathogenic bacteria, such as $S$. aureus, $P$. aeruginosa, Morganella morgaii, Bacillus subtilis, Escherichia coli and Salmonella spp. (More et al., 2012). Similarly, extracts from several plants in the genus Lasianthus (Rubiaceae) have inhibited pathogenic bacteria especially in strains of $P$. aeruginosa and which one related to traditional infectious diseases (Napiroon et al., 2017a; Napiroon et al., 2017b). Thus, these authors have explained that scopoletin seems to be an effective antimicrobial as proved by the bioassays. From cytotoxicity reports, scopoletin was relatively nontoxic on McCoy fibroblast cell lines, showing its $\mathrm{IC}_{50}$ of $132.50 \mu \mathrm{g} / \mathrm{mL}$ (Hayes and Orr, 1983).
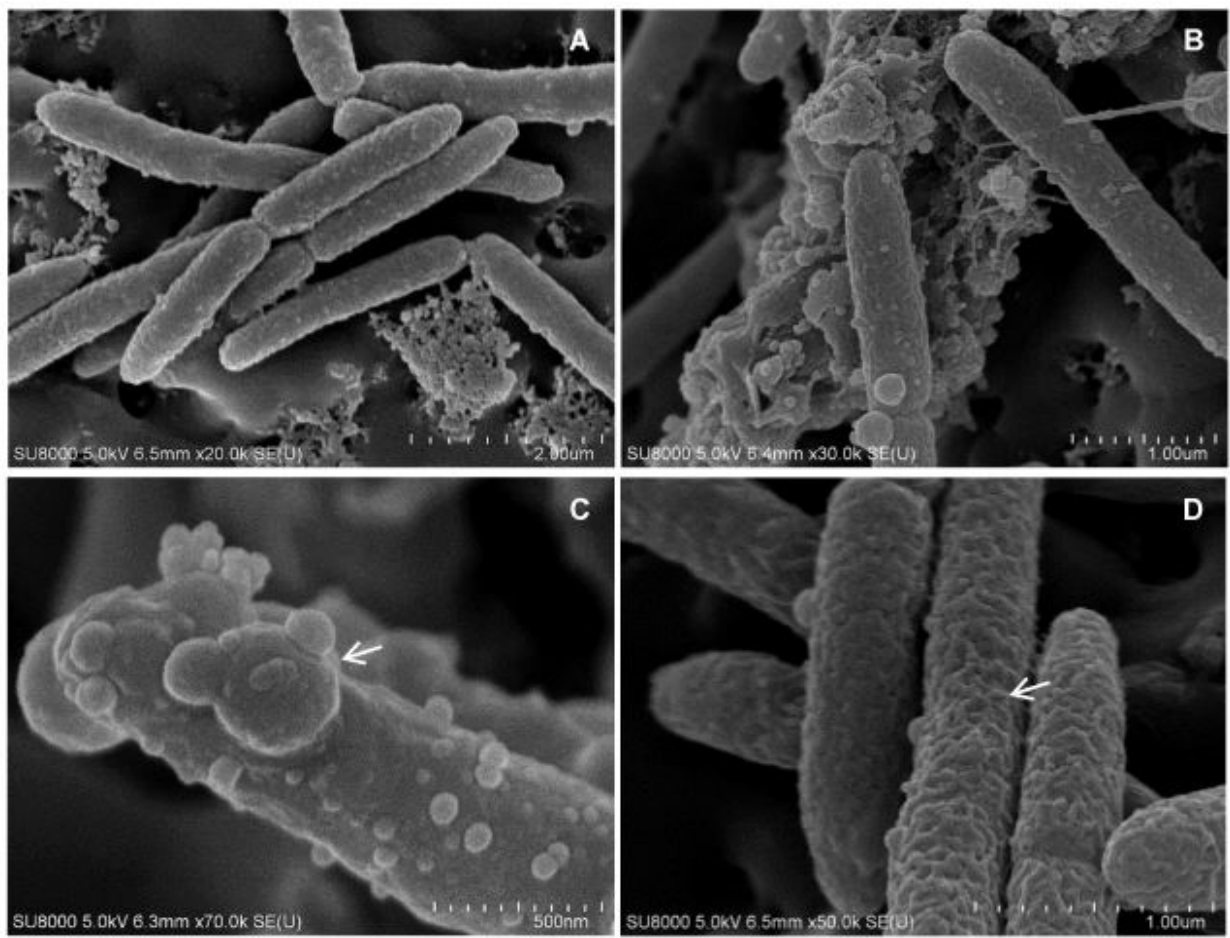

Fig. 4: FE-SEM images of Pseudomonas aeruginosa (AmpC $\beta$-lactamase producing strain); A. Cells in the absence of compounds (control), B. Cells in stem bark extract showed cell lysis and inflated swelling on cell walls, C. and D. Cells after treatment with scopoletin isolated from stem bark extracts. Note: cell walls showed inflated swelling (C) and cell walls sinking into cells (D).

Our study revealed the effect L. lucidus lipophilic extracts and its pure compound, scopoletin, from stem bark extract on $P$. aeruginosa for the first time. The stem bark lipophilic extracts and scopoletin had activity against $P$. aeruginosa even at low concentration $(128 \mu \mathrm{g} / \mathrm{ml})$ which therefore can be used as an effective source of antibacterial agents. In addition, we found morphological cellular changes documented by electron microscopy. Inflated swelling cell walls, prolonged cells and the leakage of content were observed. These phenomena seem to be similar to the mechanisms of antibiotics in $\beta$-lactam group, which inhibit penicillin-binding proteins leading to deformed cell wall structure such as elongation, lesions, and lysis (Hayes and Orr, 1983; Cardozo et al., 2013). Thus, scopoletin might serve as a hopeful antibacterial agent when further developed to use as antibiotic sources.

\section{CONCLUSION}

The scopoletin isolated from stem bark lipophilic extracts of L. lucidus showed significant antibacterial properties in a similar manner; from this action morphological changes could be observed on bacterial cells after treating with compounds. The lipophilic extracts showed pronounced anti-pseudomonas activity against $P$. aeruginosa, which could explain the use of the plant in treating fevers and wound infections caused by bacteria such as $P$. aeruginosa. The biological activity of $L$. lucidus found in this study was attributed to its high concentration of scopoletin $1.4 \mu \mathrm{mol} / \mathrm{g}$ from stem bark (200 g dry weight). The MIC results of scopoletin in this study showed activity as an anti-Pseudomonas agent. The analytical methods used in this study showed also reproducible compound patterns useful to identify scopoletin and other coumarins in Lasianthus.

\section{PATENT}

This work has received the petty patent no. 14069 from Department of Intellectual property, Thailand in July 2018 .

\section{ACKNOWLEDGMENT}

The authors would like to thank the authorities of the Department of National park Wildlife and Plant Conservation, Thailand. The Forest Herbarium (BKF), Aarhus University Herbarium, Denmark (AAU), Queen Sirikit Botanic Garden Herbarium, Chiang Mai (QBG), Princes of Songkla University Herbarium (PSU) and Kew Herbarium, London (K). 


\section{CONFLICT OF INTERESTS}

No potential conflict of interest was reported by the authors.

\section{FUNDING SOURCES}

This research was supported by postdoctoral researcher fellowship from the Carlsberg Foundation, Aarhus University, Denmark under the Flora of Thailand Project and Kasetsart University Research and Development Institute (KURDI).

\section{REFERENCES}

Adesina SK. Studies on a nigerian herbal anticonvulsant recipe. Int J Crude Drug Res, 1982; 20:93-100.

Booth NL, Nikolic D, Richard B, Breemen V, Geller SE, Banuvar S, Shulman LP, Farnsworth NR. Confusion regarding anticoagulant coumarins in dietary supplements. Clin Pharmacol Ther, 2004; 76:511-16.

Cai ZQ, Rijkers T, Bongers F. Phytosynthetic acclimation to light changes in tropical monsoon forest woody species differing in adult stature. Tree Physiol, 2005; 25:1023-1031.

Cardozo VF, Oliveira AG, Nishio EK, Perugini MR, Andrade CG, Silveira WD, Durán N, Andrade G, Kobayashi RKT, Nakazato G. Antibacterial activity of extracellular compounds produced by a Pseudomonas strain against methicillin-resistant Staphylococcus aureus (MRSA) strains. Ann Clin Microbiol Antimicrob, 2013; 12:1-8.

Chang WC, Wu SC, Xu KD, Liao BC, Wu JF, Cheng AS. Scopoletin protects against methylglyoxal-induced hyperglycemia and insulin resistance mediated by suppression of advanced glycation endproducts (AGEs) generation and anti-glycation. Molecules, 2015; 20:2786-801.

Dai Y, Liu Y, Rakotondraibe LH. Novel bioactive natural products isolated from Madagascar plants and marine organism (20092017). Chem Pharm Bull, 2018; 66(5):469-482.

Deng S, Palu AK, West BJ, Su CX, Zhou BN, Jensen JC. Lipoxygenase inhibitory constituents of the Fruits of Noni (Morinda citrifolia ) collected in Tahiti. J Nat Prod, 2007; 70:859-62.

Ferdinal N, Alfajri R, Arifin B. Isolation and characterization of scopoletin from the bark of fagraea ceilanica Thumb and Antioxidants tests. IJASEIT. 2015; 5:126-130.

Gnonlonfin GJB, Sanni A, Brimer L. Review Scopoletin - A Coumarin Phytoalexin with Medicinal Properties. Crit Rev Plant Sci, 2012; 31:47-56.

Handy ESC, Pukui MK, Livermore K. 1934. Outline of Hawaiian Physical Therapeutics. Hawaii, USA: Bernice P. Bishop Museum Bulletin.

Hayes MV, Orr DC. Mode of action of ceftazidime: affinity for the penicillin-binding proteins of Escherichia coli K12, Pseudomonas aeruginosa and Staphylococcus aureus. J Antimicrob Chemother, 1983; 12:119-126.

Ishikura N, Sugahara K, Kurosawa K. Eriodictyol-7-glucoside and Other Phenolics in the Blue Fruits of Lasiauthus japonica. Notizen, 1979; 34:628-629.

Kupiec T. Quality-control analytical method: High-performance liquid chromatography. Int J Pharm Compd, 2004; 8:223-227.

Lukasz C, Monika WH. Two-dimensional thin-layer chromatography in the analysis of secondary plant metabolites. J Chromatogr, 2009; 1216:1035-1052.

McClatchey W. From Polynesian healers to health food stores: changing perspectives of Morinda citrifolia (Rubiaceae). Integr Cancer Ther, 2002; 1:110-20.

Moon PD, Lee BH, Jeong HJ, An HJ, Park SJ, Kim RH, Ko SG, Um JY, Hong SH, Kim HM. Use of scopoletin to inhibit the production of inflammatory cytokines through inhibition of the $\mathrm{IkB} / \mathrm{NF}-\mathrm{kB}$ signal cascade in the human mast cell line HMC-1. Eur J Pharmacol, 2007; 555:218-25.

More G, Lall N, Hussein A, Tshikalange TE. Antimicrobial Constituents of Artemisia afra Jacq. ex Willd. against Periodontal Pathogens. Complementary Altern Med, 2012; 2012:1-7.

Morita Y, Tomida J, Kawamura Y. Responses of Pseudomonas aeruginosa to antimicrobials. Front Microbiol, 2014; 4:1-8.
Murray RDH, Mendez J, Brown SA. 1982. The Natural Coumarins.Occurrence, Chemistry and Biochemistry. Chichester, UK: John Wiley and Sons.

Napiroon T, Balslev H, Duangjai S, Sookchaloem D, Chayamarit K, Santimaleeworagun W, Vajrodaya S. Southeast Asian J Trop Med Public Health, 2017a; 48:117-123.

Napiroon T, Vajrodaya S, Santimaleeworagun W, Balslev H, Chayamarit K. Antibacterial Activity of Three Medicinal Lasianthus (Rubiaceae) Extracts on Human Resistant Pathogenic Bacteria. Eur Exp Biol, 2017b; 7(6):1-7.

Nawrot DA, Randrianarivelojosia M, Langat MK, Mulholland DA. Coumarins from the Malagasy Cedrelopsis rakotozafyi Cheek and Lescot (Rutaceae). Biochem Syst Ecol, 2013; 50:452-454.

Obasi SC, Njoku OU, Obidoa O, Ononogbu IC. Effects of single oral doses of scopoletin and aflatoxin B1 on the bleeding time, serum cholesterol and phospholipid levels of guinea pigs. Nutr Res, 1996; 16:667-72.

Official Journal of the European Union, Commission Decision of 5 June 2003 authorising the placing on the market of "noni juice" (juice of the fruit of Morinda citrifolia L.) as a novel food ingredient under Regulation (EC) No 258/97. 2003. Available at: https://publications. europa.eu/en/publication-detail/-/publication/cbc08fa3-7b1e-485c-9ee5dcbc474b9f23/language-en. [Accessed 5 April 2018].

Ojewole JAO, Adesina SK. Cardiovascular and neuromuscular actions of scopoletin from Tetrapleura tetraptera. Planta Med, 1983; 49:99102.

Panda S, Kar A. Isolation of scopoletin from Aegle marmelose leaves and evaluation of its antithyroidal, antioxidative and antihyperglycemic potential in hyperthyroid rats. Phytother Res, 2006; 20:1103-5.

Rai PK, Lalramnghinglova $\mathrm{H}$, Threatened and less known ethnomedicinal plants of an Indo-Burma hotspot region: conservation implications. Environ Monit Assess, 2011; 178:53-62.

Robbrecht E. Tropical woody Rubiaceae. Opera bot, 1988; 1:132-193.

Souza SM, Monacheb FD, Artur SJ. Antibacterial Activity of Coumarins Z Naturforsch C, 2005; 60c:693-700.

Tal B, Robeson DJ. The induction, by fungal inoculation of ayapin and scopoletin biosynthesis in Helianthus annuus. Phytochemistry, $1985 ; 25: 77-9$

Vajrodaya S. 1998. Comparative phytochemistry analyses within the genus Glycosmis (Rutaceae-Citroideae). Doctoral Dissertation. Vienna, Austria: University of Vienna.

Vajrodaya S, Bacher M, Greger H, Hofer O. Organ-specific chemical differences in Glycosmis trichantera. Phytochemistry, 1998; 48:897-902.

Vasconcelos JMJ., Silva AMS., Cavalejro JAS. Chromosones and flavanones from Artemisia campestris subsp. Maritima. Phytochemistry, 1998; 49:1423-24.

World Health Organization (WHO). 2017. WHO publishes list of bacteria for which new antibiotics are urgently needed. [ONLINE] Available at: http://www.who.int/news-room/detail/27-02-2017-whopublishes-list-of-bacteria-for-which-new-antibiotics-are-urgently-needed. [Accessed 12 March 2018].

Xia Y, Dai Y, Wang Q, Liang H. Determination of scopoletin in rat plasma by high performance liquid chromatography method with UV detection and its application to a pharmacokinetic study. J Chromatogr B, 2007; 857:332-6.

Zhu H, Roos MC, Ridsdale CE. A taxonomic revision of the Malesian species of Lasianthus (Rubiaceae). Blumea, 2012; 57:1-102.

How to cite this article:

Napiroon T, Bacher M, Balslev H, Tawaitakham K, Santimaleeworagun W, Vajrodaya S. Scopoletin from Lasianthus lucidus Blume (Rubiaceae): A potential antimicrobial against multidrug-resistant Pseudomonas aeruginosa. J App Pharm Sci, 2018; 8(09): 001-006. 